\title{
Analisa Pengaruh Kecepatan Kendaraan Terhadap Derajat Kejenuhan di Jalan Perkotaan pada Kawasan Pendidikan (Studi Kasus: Jalan Depan Universitas Pendidikan Indonesia)
}

\author{
Mutia Lisya ${ }^{1}$, Nuryasin Abdillah ${ }^{2}$ \\ 1) 2) Program Studi Teknik Sipil, Sekolah Tinggi Teknologi Dumai \\ Jl. Utama Karya Bukit Batrem II \\ Email: mutialisyaa1@gmail.com
}

\begin{abstract}
ABSTRAK
Kota Bandung juga dikenal sebagai Kota Pendidikan. Jalan raya Kota Bandung khususnya sepanjang jalan Dr. Setiabudi merupakan salah satu ruas jalan yang menjadi kawasan pusat pendidikan. Disepanjang ruas jalan Dr. Setiabudi terdapat beberapa perguruan tinggi salah satunya adalah Universitas Pendidikan Indonesia. Kendaraan keluar masuk kampus menjadi salah satu penyebab terjadinya antrian serta tundaan pada jalan tersebut terutama pada jam sibuk saat mahasiswa pergi dan pulang kuliah. Penelitian ini bertujuan untuk menganalisa hubungan derajat kejenuhan akibat pengaruh kecepatan. Didapatkan model persamaan hubungan derajat kejenuhan akibat pengaruh kecepatan untuk arah Sukajadi ke Lembang $\mathrm{Y}=0,7121-0,0274 . \mathrm{X}$, dengan koefisien determinasi $\left(\mathrm{r}^{2}\right)$ sebesar 79,57\% dan thitung $=17,4448$ dan ttabel $=2,011$. Model persaman hubungan derajat kejenuhan akibat pengaruh kecepatan untuk arah Lembang menuju Sukajadi Y $=1,3526$ - 0,0577.X, dengan koefisien determinasi $\left(\mathrm{r}^{2}\right)$ sebesar 0,6849 dan perbandingan nilai thitung $=62,6998$ dan $\mathrm{t}_{\text {tabel }}=2,001$.
\end{abstract}

Kata kunci: Derajat Kejenuhan, Kecepatan, Waktu Tempuh, Regresi Linier.

\begin{abstract}
The city of Bandung is also known as the City of Education. Jalan Raya Bandung, especially along Jalan Dr. Setiabudi is one of the roads that is used as a central area of education centers. Along the road Dr. Setiabudi has many universities, one of which is the Indonesian Education University. Vehicles in and out of campus are one of the causes of queues and delays on the road, especially at certain hours when students go to and from college. This study aims to analyze the relationship between the degree of saturation due to the influence of speed. The equation model of the relationship of the degree of saturation due to the influence of speed for the direction of Sukajadi to Lembang $Y=0.7121-0.0274 . X$, with a coefficient of determination ( $r 2$ ) of $79.57 \%$ and $t_{\text {count }}=17.4448$ and $t_{\text {table }}=2.011$. The equation model of the relationship of the degree of saturation due to the influence of speed for the direction of Lembang to Sukajadi $Y=1.3526$ - 0.0577.X, with a coefficient of determination (r2) of 0.6849 and a comparison of the values of $t_{\text {count }}=62.6998$ and $t_{\text {table }}=2.001$.
\end{abstract}

Keywords: Saturation of Degree, Speed, Travel Time, Linear Regression. 


\section{Pendahuluan}

Kota Bandung merupakan salah satu kota metropolitan, selain itu Kota Bandung juga dikenal sebagai Kota Pendidikan (City of Education). Jalan raya Kota Bandung khususnya sepanjang jalan Dr. Setiabudi merupakan salah satu pusat Pendidikan di Kota Bandung. Disepanjang ruas jalan Dr. Setiabudi terdapat banyak sekolah dan perguruan tinggi diantaranya Universitas Pendidikan Indonesia, Universitas Pasundan, dan Sekolah Tinggi Pariwisata Bandung. Kendaraan keluar masuk kampus menjadi salah satu penyebab terjadinya antrian serta tundaan pada jalan tersebut. Selain itu, disepanjang ruas jalan Dr. Setiabudi juga terdapat pusat perbelanjaan yang lahan parkirnya tidak cukup memadai sehingga kendaraan banyak yang parkir di bahu jalan. Hal ini tentu saja menciptkan tundaan, serta antrian pada jalan tersebut sehingga arus lalu lintas cenderung padat, terutama pada jam sibuk saat mahasiswa/i berangkat dan pulang kuliah.

Panjang jalan Dr. Setiabudi sekitar 4,2 km merupakan jalan kolektor primer. Pada ruas jalan Dr. Setiabudi disegmen jalan depan Universitas Pendidikan Indonesia (UPI) memiliki karakteristik jalan 4 lajur 2 arah (2/4UD) dan sering terjadi kemacetan yang disebabkan oleh peningkatan volume lalu lintas dan besarnya hambatan samping. Dengan meningkatnya volume kendaraan pun yang melewati jalan tersebut menyebabkan kecepatan kendaraan menurun sehingga waktu tempuh untuk menempuh ruas jalan Dr. Setiabudi semakin besar terutama pada jam sibuk. Meningkatnya volume kendaraan dapat mempengaruhi tingkat kinerja lalu lintas, hal ini akan menyebabkan perubahan perilaku lalu lintas pada ruas jalan dan akan menimbulkan masalah lalulintas (Fahmi, Kurniawan and Idham, 2020).

Agar dapat menyelesaikan masalah transportasi tersebut, perlu dilakukan kajian terhadap perilaku karakteristik lalulintas. Terdapat 3 parameter utama dalam merepresentasikan karakteristik arus lalu lintas yang saling berhubungan secara matematis, yaitu kecepatan, volume dan kepadatan (Tamin, 2008). Indikator lainya dari kinerja lalu lintas adalah derajat kejenuhan (DS). Dimana besaranya secara teoritis tidak diizinkan lebih dari 1, dimana kondisi ruas jalan tersebut sudah mendekati jenuh jika nilai derajat kejenuhanya (DS) mendekati nilai 1 (Khairulnas, 2018).

\section{Metode Penelitian}

Penelitian dilakukan pada ruas jalan Dr. Setiabudi disegmen jalan depan Universitas Pendidikan Indonesia (UPI). Survei lapangan yang dilakukan untuk pengumpulan data dibagi dua yaitu survei volume kendaraan dan survei kecepatan kendaraan. Masing-masing survei dilakukan dengan membagi jenis kendaraan menjadi kendaraan ringan (LV), kendaraan berat (HV) dan kendaraan bermotor (MC). Survei volume kendaraan dilakukan dengan menghitung kendaraan yang melewati garis pengamatan yang direkam menggunakan kamera action cam selama jam puncak 16.00 - 17.00 WIB. Rekap data volume lalu lintas dilakukan menggunakan bantuan The KMPlayer dan Microsoft Excel. Perekapan data volume lalu lintas dilakukan untuk setiap interval waktu 15 menit. Pengambilan data kecepatan kendaraan dilakukan langsung dilapangan dengan mencatat waktu 
tempuh kendaraan yang melewati panjang segmen tertentu dalam penelitian ini 30 m. Kecepatan kendaraan yang digunakan pada penelitian ini ialah kecepatan kendaraan setempat (spot speed). Dan data dianalisis dengan menggunakan Space mean speed (SMS) dimana dihitung rata-rata kecepatan kendaraan yang menempati suatu segmen jalan pada interval waktu tertentu dengan menggunakan rumus seabagi berikut:

Keterangan:

$$
V S=\frac{n . L}{\sum_{i=1}^{n} t i}
$$

$$
\begin{array}{ll}
\mathrm{V}_{\mathrm{s}} & =\text { spot speed } \\
\mathrm{n} & =\text { banyak kendaraan yang melewati segmen } \\
\mathrm{L} & =\text { panjang segmen yang ditinjau } \\
\mathrm{t}_{\mathrm{i}} & =\text { waktu tempuh kendaraan yang melewati segmen }
\end{array}
$$

Kapasitas merupakan arus maksimum dalam satuan smp/jam yang dapat dipertahankan melalui suatu bagian jalan per satuan waktu pada kondisi tertentu. Nilai kapasitas didapatkan melalui survei lapangan (Anonim, 1997). Persamaan dasar yang digunakan untuk menghitung kapasitas adalah sebagai berikut:

$$
\mathrm{C}=\mathrm{Co}_{\mathrm{O}} \times \mathrm{FC}_{\mathrm{W}} \times \mathrm{FC}_{\mathrm{SP}} \times \mathrm{FC}_{\mathrm{SF}} \times \mathrm{FC}_{\mathrm{CS}}
$$

Keterangan:

$$
\begin{array}{ll}
\mathrm{C} & =\text { Kapasitas (smp/jam) } \\
\mathrm{C}_{\mathrm{O}} & =\text { Kapasitas dasar (smp/jam) } \\
\mathrm{FC}_{\mathrm{W}} & =\text { Faktor penyesuaian lebar jalan } \\
\mathrm{FC}_{\mathrm{SP}} & =\text { Faktor penyesuaian pemisahan arah (untuk jalan tidak terbagi) } \\
\mathrm{FC}_{\mathrm{SF}} & =\text { Faktor penyesuaian hambatan samping dan bahu jalan/kereb } \\
\mathrm{FC}_{\mathrm{CS}} & =\text { Faktor penyesuaian ukuran kota }
\end{array}
$$

Dengan melakukan survei volume lalu lintas, kecepatan kendaraan dan waktu tempuh diperoleh data hasil pengamatan yang kemudian dianalisa menggunakan teori aliran lalu lintas melalui hubungan antara kecepatan dan derajat kejenuhan (DS). Dimana derajat kejenuhan (DS) didapatkan dari hasil bagi dari arus lalu lintas (Q) dengan kapasitas (C).

Metode statistik analisa regresi linier sederhana digunakan untuk melihat hubungan antara kecepatan dengan derajat kejenuhan (DS). Analisis regresi sederhana digunakan untuk mengetahui apakah terdapat hubungan dari variabel independent terhadap variabel dependent (Sugiyono, 2017). Regresi linier sederhana adalah perhitungan time series dengan metode kuantitatif. Berikut persamaan dasar metode regresi linier sederhana:

$$
Y=a+b X
$$

Keterangan:

$$
\begin{array}{ll}
Y & =\text { Variabel Dependent } \\
a & =\text { Konstanta } \\
b & =\text { Koefisien variabel } X \\
X & =\text { Variabel Independent }
\end{array}
$$

Untuk melihat kempuan fungsi regresi linier sederhada dalam menaksir nilai aktual dari sampel dinilai dengan melihat Goodness of Fit-nya. Pada penelitian ini digunakan nilai koefisien determinasi $\left(\mathrm{r}^{2}\right)$, dan nilai statistik t. Koefisien determinasi $\left(\mathrm{r}^{2}\right)$ adalah besaran yang digunakan untuk menunjukkan kekuatan hubungan antara 
dua variabel atau lebih dalam persentase atau untuk menunjukan seberapa besar variabel independent dapat mempengaruhi variabel dependent. Nilai koefisien determinasi $\left(\mathrm{r}^{2}\right)$ didapatkan dengan mengkuadratkan nilai koefisien korelasi $(\mathrm{r})$.

$$
\begin{aligned}
& r=\frac{(n \cdot \Sigma x y-\Sigma x \cdot \Sigma y)^{2}}{\sqrt{\left(n \cdot \Sigma x^{2}-(\Sigma x)^{2}\right) \cdot\left(n \cdot \Sigma y^{2}-(\Sigma y)^{2}\right)}} \\
& r^{2}=\frac{b(n \cdot \Sigma x \cdot y-(\Sigma x)(\Sigma y))}{n \cdot \Sigma y^{2}-(\Sigma y)^{2}}
\end{aligned}
$$

$$
\begin{array}{ll}
\text { Keterangan: } \\
r & =\text { Koefisien Korelasi } \\
\mathrm{x} & =\text { Variabel Independent } \\
\mathrm{y} & =\text { Variabel Dependent } \\
\mathrm{n} & =\text { Banyaknya sampel }
\end{array}
$$

Untuk memudahkan dalam menginterpretasikan tingkat kekuatan hubungan antara variabel independent terhadap variabel dependen diberikan kriteria sebagai berikut (Sudjana, 2016):

1. $0,9<\mathrm{r}<1$ (hubungan antar variabel sangat kuat)

2. $0,7<\mathrm{r}<0,9$ (hubungan antar variabel kuat)

3. $0,4<\mathrm{r}<0,7$ (hubungan antar variabel sedang)

4. $0,2<\mathrm{r}<0,4$ (hubungan antar variabel lemah)

5. $0<\mathrm{r}<0,2$ (hubungan antar variabel sangat lemah)

6. $\mathrm{r}=0$ (tidak memiliki hubungan antar variabel)

Uji t digunakan untuk mengetahui seberapa tinggi pengaruh antara variabel independent secara individual dalam mendeskripsikan variansi variabel independent (Ghozali, 2011). Adapun rumus dasar yang digunakan untuk menguji hipotesis dalam uji t menurut (Sugiyono, 2017) adalah sebagai berikut:

$$
t=\frac{r \sqrt{n-2}}{\sqrt{1-r^{2}}}
$$

Keterangan:

$$
\begin{array}{ll}
\mathrm{t} & =\text { nilai uji thitung } \\
\mathrm{r} & =\text { koefisien korelasi } \\
\mathrm{r}^{2} & =\text { koefisien determinasi } \\
\mathrm{n} & =\text { jumlah sampel yang diobservasi }
\end{array}
$$

Dengan menggunakan rumus tersebut didapatkan nilai thitung kemudian dibandingkan dengan tabel pada taraf signifikansi $\alpha$ (0.05). Nilai tabel didapatkan dengan menggunakan tabel statistik nilai t pada degree of freedom tertentu ( $\mathrm{df}=\mathrm{n}-\mathrm{k}$; $\mathrm{n}=$ jumlah data; $\mathrm{k}=$ jumlah independent dan variabel dependent). Untuk membuktikan hipotesis ini didefinisan sebagai berikut:

$\mathrm{H}_{0} \quad=$ variabel independent secara individual tidak mempengaruhi variabel dependent.

$\mathrm{H}_{1} \quad=$ variabel independent secara individual mempengaruhi variabel dependent . 
Unitek : Jurnal Universal Teknologi

Vol.14 No.2 Juli - Desember 2021

e-ISSN : 2580-2582, p-ISSN: 2089-3957 berikut:

Untuk dasar dalam pengambilan keputusan dari hasil uji t adalah sebagai

1. Jika thitung $<t_{\text {tabel }}, \mathrm{H}_{0}$ diterima; $\mathrm{H}_{1}$ ditolak

2. Jika thitung $>t_{\text {tabel }}, \mathrm{H}_{1}$ diterima; $\mathrm{H}_{0}$ ditolak

\section{Hasil dan Pembahasan}

Survei volume lalulintas dilakukan pada saat jam puncak dari arah Sukajadi ke Lembang dengan jumlah volume lalulintas sebesar 1946,60 smp/jam dan volume lalulintas pada jam puncak untuk arah dari Lembang ke Sukajadi sebesar 1534,85 smp/jam.

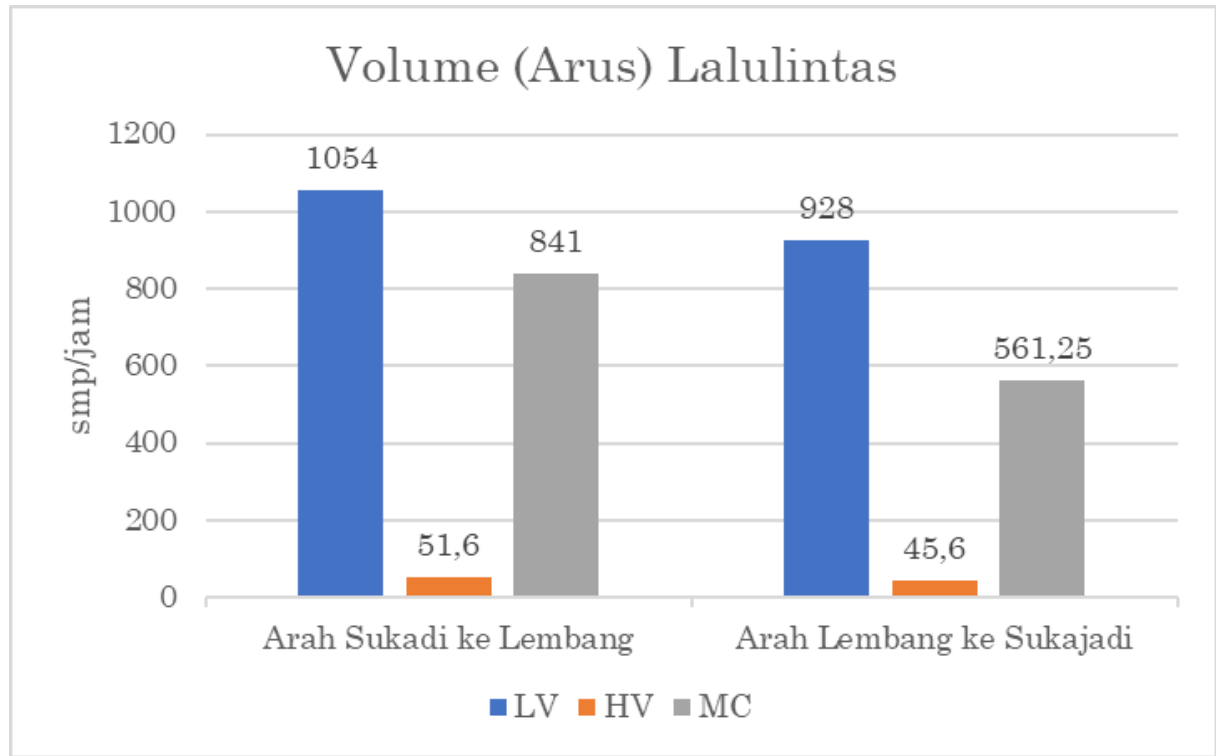

Gambar 1. Data volume lalulintas

Kapasitas (C) untuk jalan Dr. Setiabudi dengan karakteristik empat-lajur duaarah tidak terbagi:

Tabel 1. Kapasitas jalan Dr. Setiabudi

\begin{tabular}{cccccc}
\hline $\begin{array}{c}\text { Kapasitas } \\
\text { Dasar }\end{array}$ & \multicolumn{3}{c}{ Faktor penyesuaian Kapasitas } & Kapasitas \\
\hline Co & $\mathrm{F}_{\mathrm{CW}}$ & $\mathrm{FC}$ SP & $\mathrm{FC}_{\mathrm{SF}}$ & $\mathrm{FC}_{\mathrm{CS}}$ & $\mathrm{C}$ \\
\hline $\begin{array}{c}1500 \times 2= \\
3000\end{array}$ & 1,09 & 1 & 0,91 & 1 & $2.975,7$ \\
\hline
\end{tabular}
berikut:

Dengan menggunakan rumus dasar maka didapatkan kapasistas (C) sebagai

$\mathrm{C}=\mathrm{C}_{\mathrm{O}} \times \mathrm{FC}_{\mathrm{W}} \times \mathrm{FC}_{\mathrm{SP}} \times \mathrm{FC}_{\mathrm{SF}} \times \mathrm{FC}_{\mathrm{CS}}$

$=3000 \times 1,09 \times 1 \times 0,91 \times 1$

$=2.975,7$

$=2.976 \mathrm{smp} / \mathrm{jam}$ 
Dari hasil analisis yang dilakukan pada lokasi penelitian di jalan Dr. Setiabudi khususnya di segmen jalan depan Universitas Pendidikan Indonesia didapatkan:

1. Persamaan umum yang didapatkan dari hasil analisa regresi linier sederhana hubungan antara kecepatan kendaraan (S) dan derajat kejenuhan (Ds) di jalan Dr. Setiabudi dari arah Sukajadi ke arah Lembang adalah Y = 0,7121 - 0,0274.X, dengan koefisien determinasi $\left(\mathrm{r}^{2}\right)$ sebesar 0,7957. Hal ini menyatakan bahwa sebesar $79,57 \%$ variabel independent dapat menjelaskan varians dari variabel dependent. Terdapat 20,43\% (100\%-79,57\%) varians variabel dependent yang dijelaskan oleh faktor lain. Dari nilai koefisien determinasi yang didapatkan diketahui hubungan antara variabel independent dan variabel dependentnya tinggi, dimana nilainya mendekati 1 dan sebaliknya jika nilainya mendekati 0 berarti huubungan antara variabel semakin lemah.

Dari hasil pengujian didapatkan perbandingan nilai thitung $=17,4448$ dan tabel $=2,011$ (dengan pengujian 2 sisi dan taraf signifikansi (a) $=0,05$ dengan derajat kebebasan $(\mathrm{dk}) \mathrm{n}-\mathrm{k}-1=50-1-1=48)$ maka thitung $>t_{\text {tabel. }}$ Sehingga dari hasil uji t ini dapat disimpulan bahwa variabel independent secara individual berpengaruh terhadap variabel dependent.

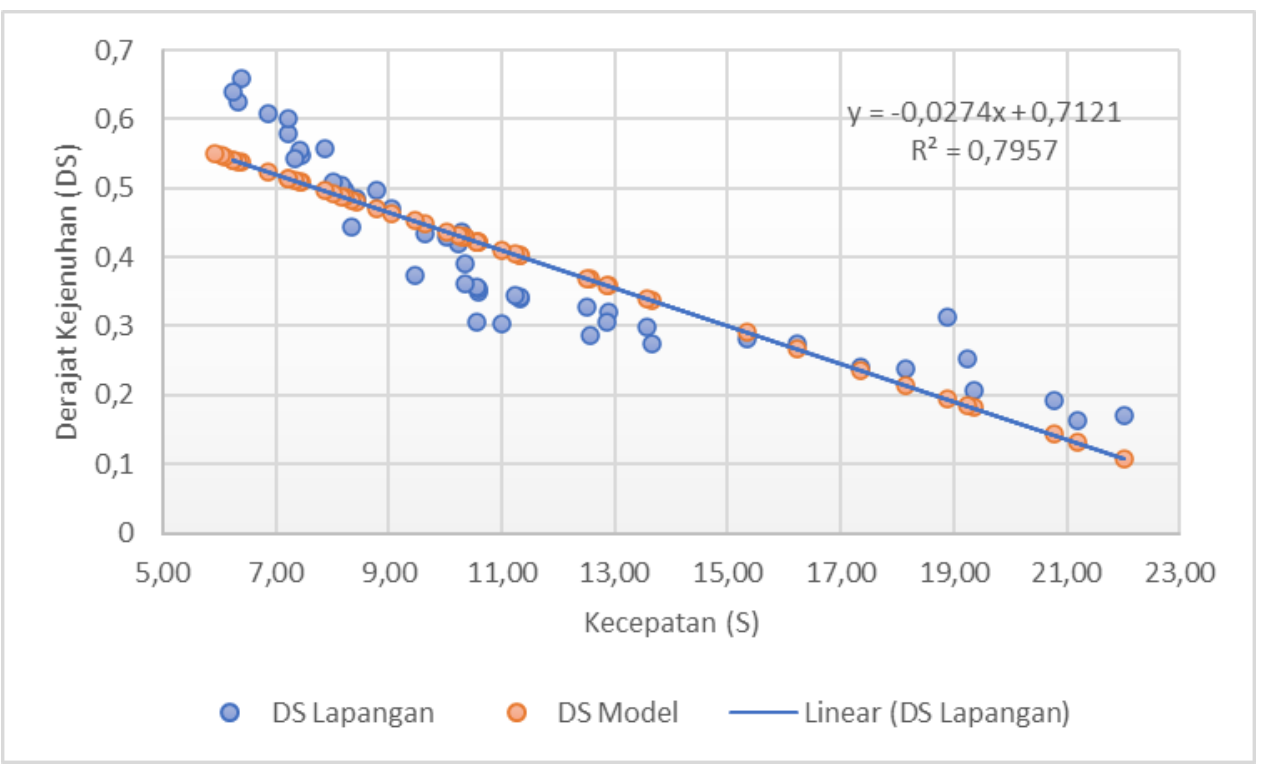

Gambar 2. Hubungan kecepatan dan derajat kejenuhan arah Sukajadi - Lembang

2. Persamaan umum yang didapatkan dari hasil analisa regresi linier sederhana hubungan antara kecepatan kendaraan (S) dan derajat kejenuhan (Ds) di jalan Dr. Setiabudi dari arah Lembang ke arah Sukajadi adalah Y = 1,3526 - 0,0577.X, dengan koefisien determinasi $\left(\mathrm{r}^{2}\right)$ sebesar 0,6849. Hal ini menyatakan bahwa sebesar $68,49 \%$ variabel independent dapat menjelaskan varians dari variabel dependent. Terdapat 31,51\% (100\%-68,49\%) varians variabel dependent yang dijelaskan oleh faktor lain. Dari nilai koefisien determinasi yang didapatkan diketahui hubungan antara variabel 
independent dan variabel dependentnya tinggi, dimana nilainya mendekati 1 dan sebaliknya jika nilainya mendekati 0 berarti huubungan antara variabel semakin lemah.

Dari hasil pengujian didapatkan perbandingan nilai thitung $=62,6998$ dan tabel $=2,001$ (dengan pengujian 2 sisi dan taraf signifikansi (a) $=0,05$ dengan derajat kebebasan $(\mathrm{dk}) \mathrm{n}-\mathrm{k}-1=50-1-1=48)$ maka thitung $>t_{\text {tabel. }}$. Sehingga dari hasil uji t ini dapat disimpulan bahwa variabel independent secara individual berpengaruh terhadap variabel dependent.

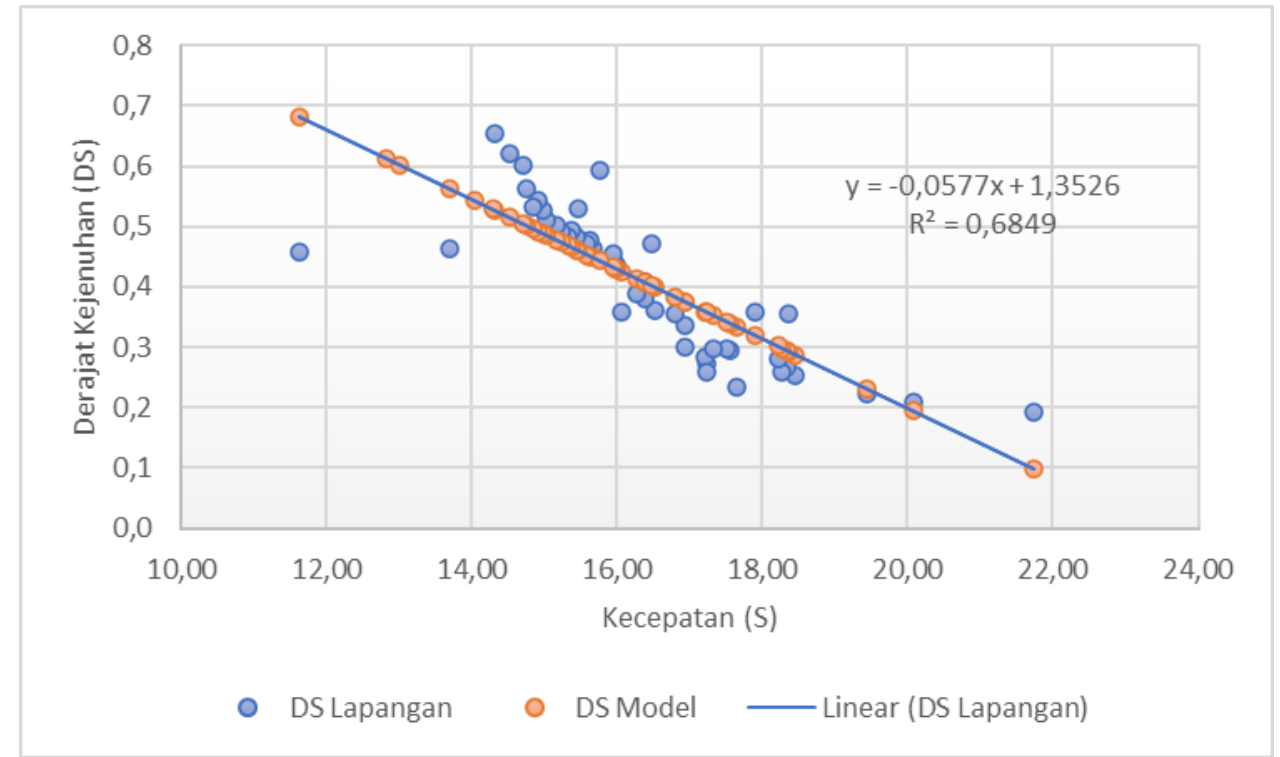

Gambar 3. Hubungan kecepatan dan derajat kejenuhan arah Lembang - Sukajadi

\section{Simpulan}

Dari hasil analisis menggunakan model regresi linier sederhana didapatkan tingkat derajat kejenuhan di jalan Dr. Setiabudi menggunakan persamaan $\mathrm{Y}=$ 0,7121 - 0,0274.X, dengan koefisien determinasi $\left(\mathrm{r}^{2}\right)$ sebesar 0,7957 untuk dari arah Sukajadi ke arah Lembang. Dan didapatkan persamaan $\mathrm{Y}=1,3526$ - 0,0577.X, dengan koefisien determinasi (r2) sebesar 0,6849 untuk dari arah Lembang ke Sukajadi. Dari nilai koefisien determinasi yang didapatkan diketahui hubungan antara variabel independent dan variabel dependentnya tinggi, dimana nilainya mendekati 1 dan sebaliknya jika nilainya mendekati 0 berarti huubungan antara variabel semakin lemah. Dengan memasukan kecepatan kendaraan kedalam nilai X maka dapat diketahui derajat kejenuhan (DS). Dari model persamaan regresi linier sederhana tersebut dapat ditarik kesimpulan jika derajat kejenuhan meningkat maka kecepatan kendaraan akan menurun begitu pula sebaliknya. 
Unitek : Jurnal Universal Teknologi

Vol.14 No.2 Juli - Desember 2021

e-ISSN : 2580-2582, p-ISSN: 2089-3957

\section{Daftar Pustaka}

Anonim (1997) Manual Kapasitas Jalan Indonesia, Manual Kapasitas Jalan Indonesia (MKJI).

Fahmi, I., Kurniawan, V. and Idham, M. (2020) 'Perbandingan PKJI 2014 Dan MKJI 1997 Dengan Software Vissim Dalam Menganalisa Dampak Lalu Lintas (Studi Kasus Jalan Jenderal Sudirman Duri)', Jurnal Unitek, 11(2), pp. 183-191. doi: 10.52072/unitek.v11i2.42.

Ghozali, I. (2011) 'Aplikasi Analisis Multivariate Dengan Program IBM SPSS 19 (edisi kelima)', Aplikasi Analisis Multivariate dengan program SPSS.

Khairulnas, K. (2018) 'Analisis Derajat Kejenuhan dan Tingkat Pelayanan Jalan Sudirman Kota Pekanbaru', Jurnal Teknik, 12(2), pp. 148-154. doi: 10.31849/teknik.v12i2.1824.

Sudjana (2016) 'Metoda Statistika (7th Edition)', Metoda statistika.

Sugiyono (2017) Metode penelitian pendidikan:(pendekatan kuantitatif, kualitatif dan $R \& D)$, Bandung: Alfabeta.

Tamin, O. Z. (2008) Perencanaan, Permodelan, \& Rekayasa Transportasi: Teori, Contoh Soal, dan Aplikasi, Itb. 